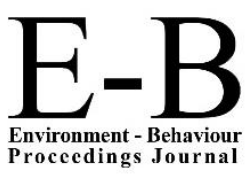

\section{AcE-Bs2016Taipei}

$7^{\text {th }}$ Asian Conference on Environment-Behaviour Studies National Taiwan University, Taipei, Taiwan, 09-10 April 2016

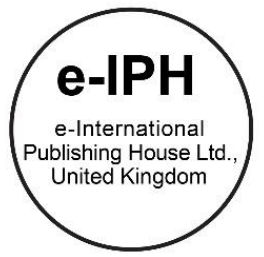

\title{
Environmental Barriers Faced by Caregivers Caring for Adults with Terminal IIInesses
}

\author{
Husna Ahmad Ainuddin ${ }^{1 *}$, Siti Norehan Ab Ghani², \\ Akehsan Dahlan ${ }^{3}$, Mohd Suleiman Murad ${ }^{4}$
}

1, 2, 3, 4, Department of Occupational Therapy, Faculty of Health Sciences, UiTM Selangor, Puncak Alam, 42300 Malaysia

\begin{abstract}
Caring for a patient at the end of their life can be highly demanding and becomes a challenge for caregivers. The participants were recruited using a convenience sampling of ten caregivers who provided the most care to an adult with a terminal illness. All interviews were recorded, transcribed verbatim and analyzed using the six steps of Interpretative Phenomenological Analysis (IPA). The findings showed that the environmental barriers caregivers had recognized were transportation, insufficient material resources, and remote home facilities. By acknowledging these barriers, healthcare professionals can design and implement therapeutic environments that are clinically relevant toward those most in need.

(c) 2016. The Authors. Published for AMER ABRA by e-International Publishing House, Ltd., UK. This is an open access article under the CC BY-NC-ND license (http://creativecommons.org/licenses/by-nc-nd/4.0/).

Peer-review under responsibility of AMER (Association of Malaysian Environment-Behaviour Researchers), ABRA (Association of Behavioural Researchers on Asians) and CE-Bs (Centre for Environment-Behaviour Studies), Faculty of Architecture, Planning \& Surveying, Universiti Teknologi MARA, Malaysia.
\end{abstract}

Keywords: Environmental barriers; terminal illness; adult; caregiver

\section{Introduction}

Increased life expectancy and other demographic changes will increase the need for long-term care even greater over the next 50 years (Janette, Dill, \& Cagle, 2010). Moreover, the older population and disabled constantly express a vivid preference to live, receive care, and die in their own homes (Stone, 2004). WHO (2004) define terminal illness as an illness for which there is no known cure. Many developed nations will face a public barrier over the coming decades in regards of how to enhance palliative and end-of-life care provision to meet the needs of rapidly ageing populations (Gardiner, Brereton, Frey, Wilkinson-Meyers \& Gott, 2014). Terminal illness such as malignant neoplasm, heart, and pulmonary conditions are expected to be a significant medical problem amongst this

\footnotetext{
* Corresponding author. Tel.: +603-32584543

E-mail address: husnaa9866@puncakalam.uitm.edu.my
}

2398-4287 @ 2016. The Authors. Published for AMER ABRA by e-International Publishing House, Ltd., UK. This is an open access article under the CC BY-NC-ND license (http://creativecommons.org/licenses/by-nc-nd/4.0/).

Peer-review under responsibility of AMER (Association of Malaysian Environment-Behaviour Researchers), ABRA (Association of Behavioural Researchers on Asians) and CE-Bs (Centre for Environment-Behaviour Studies), Faculty of Architecture, Planning \& Surveying, Universiti Teknologi MARA, Malaysia.

DOI: http://dx.doi.org/10.21834/e-bpj.v1i3.359 
population. Terminal illness is defined as the disease that is active and progressive that cannot be cured or there is no expectation of treatment recovery (Gonorazky, 2011). As the disease progresses, patients faced with the rapid deterioration in health, reduction in performance status, functional capacity, pain and psychological distress (Petkova et al., 2010) and impaired ability for self-care. Most of them often need to be in total dependency in all aspects from their family caregivers. Terminal illness patients do not only suffer themselves, but it also affects their family members. As a result of the disease, all members of the family, including the patient face significant changes in their lives that requires adjustments and adaptation in coping with the numerous degree of loss (Sherman, 1998). A study from Tse Man Wah (2007) reported four major difficulties, including the relationship with the patient, emotional reactions to caring, physical demands in caregiving and restriction in social life.

Principle caregivers are outlined as persons who often provide the most aid with one or more of the essential activities of communication, mobility, transport, house chores and self-care (Australian Bureau of Statistics, 1999). According to the National Board of Health and Welfare's of Sweden, characteristics of high quality patient-focused care stress out communication between patients, health personnel and family members (Socialstyrelsen 2008). In Sweden, the patient's perspective is essential in caregiving and family members are only able to participate so far as the patient allows (Wilhelmsson, 2011). In this challenging era, family members are commonly asked to perform clinical care responsibilities that until recently would have been performed by trained healthcare personnel (Ryn et al., 2011). A study found that caregivers had reported of the negative feelings and experiences concerning the longterm care for the care recipient (Michalik \& Valenta, 2012).Furthermore, because caregivers are challenged with both emotional difficulties and inadequate information, it is crucial for relatives to have knowledge, education, and assistance in their daily lives (Magnusson et al., 2002).

Environmental factors by definition affect large groups that in cooperates mutual living or working spaces (Woolf \& Aron, 2013). A variety of aspects of the physical and social environment can impact people's health thus contribute as explanatory factors for health differences across countries. Moreover, environmental factors related to surroundings and location may in turn add to and increase socioeconomic and ethnic health inequalities (Bleich et al., 2012; Laveist et al., 2011). Nowadays, attention is given to the implications for health behaviors and social interactions that are created by the built environment. The built environment refers to the existence of (and proximity to) health-relevant resources as well as to aspects of the ways in which communities are designed and built (including transportation systems, urban planning and design features) (Woolf and Aron, 2013). Living in socioeconomically disadvantaged communities has been linked to higher rates of injury in both adults and children (Cubbin et al., 2000). However, only recently, healthcare personnel have been faced with the dilemma of how to create the most collective value with shrinking resources (Drummond et al. 2013).

Currently, there are very limited studies on environmental barriers in caregiving locally and globally. Therefore, this present study aims to reveal the family caregivers' experience of environmental barriers in taking care of adults with a terminal illness, as understanding the experience is essential to help the patient live as comfortable as possible, as well as to provide support to the caregivers.

\section{Methodology}

This is a qualitative study which attempts to provide an exploration of one's life experiences in taking care of an adult person with a terminal illness. It was conducted using a phenomenology approach as it is well-suited to the objectives of this study to elicit further details and to understand people's life experiences (Smith, Flowers \& Larkin, 2009). The family caregivers were approached either during hospital visits or over the telephone called to schedule an interview session and invited to participate. The detail of the study was briefed accordingly, and each respondent who agreed to be interviewed was asked to fill in a written consent form. The study was approved by the ethics committee in Universiti Teknologi MARA (UiTM). In-depth interviews were conducted with the caregivers about their challenges or barriers in taking care of adults with terminal illnesses. The participants were recruited using a convenience sampling of ten caregivers who provided the most care to an adult with a terminal illness. They held a caring role for adult people aged 50 years old and above.

The researchers designed the interview guide based on Kawa's Model (Iwama et al., 2009) in which it 
metaphors the river and its structured environment to symbolize the complexity of the phenomenon. In Kawa's Model, the self is seen and treated in regards to how the self and the environment inter-relate one and another. The river is acknowledged as a symbol for the life sequence. Wherever the river flows, the profound and multifaceted inter-relation of other features of nature is introduced and become significant. As other features of nature (e.g. water, rocks, driftwood and sukima) participate in the life or flow of a river, so the river also participates in the other. Essential relationships form between all features in an environment and equilibrium comes into being (Iwama et al., 2009). Features of the river include water (life flow), walls and bottom of the river (client's environment), rocks (barriers or challenges), driftwood (personal attributes and resources) and sukima (spaces in the river). Thus, environmental barriers in this study are pictured as the rocks in the river.

The interviews were semi-structured and consisted of open-ended questions, guided by a questionnaire template developed for this study by the researcher. Participants preferred to share their story in chronological order. Thus, we obtained both a historical account of their experience and an account of the current issues and concerns experienced at the time of the interview. The interview sessions were approximately 30 minutes each. All conversations were recorded throughout the interview session using an audio recording device.

Finally for data analysis, interviews were transcribed verbatim and analysed concurrently using the six steps of Interpretative Phenomenological Analysis (IPA) as described by Smith et al. (2009) namely, transcript reading, text analysis, theme development, clustering of themes, analysis of other interviews following the first- fourth step, and finally, the authors searched for the similarities of themes across interviews. IPA recognizes that the researcher's engagement with the subject's interview scripts has an explanatory element thus it assists in understanding an individual's way of thinking (Biggerstaff \& Thompson, 2008). As such, it is particularly appropriate for healthcare providers that conduct studies with objectives that relate the research findings to significant bio-psycho-social concepts (Smith, 2004). The results are revealed through themes. Some of the quotes from interview transcripts were selected to represent the emerging themes. Forward translations of transcripts were carried out with the Malay transcripts by a professional in the field.

\section{Results}

This recent study revealed the findings conducted over ten participants with family members who were mostly involved in providing the care for adult persons with a terminal illness. The demographic characteristics of the ten family member caregivers are reported in Table 1.

Overall, of all the family caregivers who took part in the study, female caregivers were more than male caregivers who are eight and two respectively. This is in line with another study that had found that women constitute a majority of the informal caregivers of adults in need of assistance (Pinquart \& Sörensen, 2005). The age inclusion criteria for this study was 18 years and older. Four participants were in a range age of 18 to 30 years, another four participants in a range age of 31 to 40 years old, meanwhile only two participants in a range ages of 41 and older. The demographic details of participants are as below in Table 1.

Table 1. Demographic characteristics of the participants $(N=10)$

\begin{tabular}{lc}
\hline Characteristic & $\mathbf{N}(\%)$ \\
\hline Gender & \\
$\quad$ Male & $2(20)$ \\
Female & $8(80)$ \\
Age (years) & \\
$18-30$ & $4(40)$ \\
$31-40$ & $4(40)$ \\
$\geq 41$ & $2(20)$ \\
Employment Status & $3(30)$ \\
Student & $4(40)$ \\
Self-employed & $3(30)$ \\
Housewife &
\end{tabular}


Relationship to recipient

Spouse

Daughter

$6(60)$

Grandchildren

$2(20)$

The findings presented using IPA revealed three themes. It is summarized in Table 2.

Table 2. Themes emerged from the interview transcripts.

\begin{tabular}{c}
\hline Themes \\
\hline 1. Transportation \\
2. Insufficient material resources \\
3. Inconvenient home facilities \\
\hline
\end{tabular}

From this study, the respondents expressed three themes. These themes represent and illustrated a variety of underlying experiences, which are further detailed with quotes from the interviews (Smith, Flowers, \& Larkin, 2009).

\section{Theme 1: Transportation}

The caregivers seem to have experienced the problem in acquiring transport to enable them to bring the patient to their hospital appointments. Patients with terminal illnesses were frequently admitted to the emergency department or attended hospital for treatment to alleviate worsening symptoms. Using the car without proper facilities for a long journey seems to be not suitable to carry the patients since they are very fragile and their condition can become worse. In the worst situations, they need the ambulance service to bring the patients to the hospital. However, the fee charge for the private ambulance service is quite expensive. This issue is becoming an impediment for the caregivers to meet the medical requirement for the patient needs. This is illustrated by this caregiver:

I could not attend the hospital appointments anymore. My father cannot even move or sit by himself. It's very difficult to bring my father to the hospital using my car. My father becomes extremely exhausted just from the journey to the hospital. We decided to stay at home.

This was also supported by another caregiver:

All of the children are staying far from us and the hospital appointments are during working hours. Because the patient is bedridden, I don't know how to lift him up and put him in the car. The car is also not suitable for him because he has to be laid down. He needs an ambulance but the ambulance is not easy to get around here.

Theme 2: Insufficient material resources

Meanwhile, some of the caregivers claimed that they were having difficulties getting the material resources such as medical equipment and supplies for the patients' needs. Each patient requires different equipment for their care. Unable to use the suitable tools can cause other complications for the patients and the need for extra care for the caregivers. This has been illustrated by this caregiver. She said:

I'm using the large size of colostomy bags. I am already searching in all pharmacies around here. There is no suitable size for him. The stools keep leaking under the bag. I always need to monitor him because his skin becomes irritated. He also got admitted because of infections. 
Another caregiver said:

She cannot eat anymore. In the hospital, the nurse had given her the special milk. I have already requested the milk from the hospital, but they ask me to buy by myself. The problem is I could not find that kind of milk.

\section{Theme 3: Inconvenient home facilities}

Apart from that caregivers also reported that the inconvenient home facilities increase their workload to take care of the patient at home. This is illustrated by the caregiver who was taking care of her father who has severe complications of the diabetes mellitus disease. She explained:

My father's condition became worse. Now he depends on the wheelchair for his mobility. However, our home condition is not suitable for the wheelchair users. Therefore, we need to carry him, especially to go to the toilet. If he can use the wheelchair, of course it will reduce our burden since he can do it by himself. All we need to do is just minimal supervision to avoid any accidents.

\section{Discussion}

The present study has highlighted the nature of family caregivers' environmental barriers in taking care of an adult with a terminal illness. One theme that emerged in this study is due to the transportation issue. Most patients are staying at home because makes it easier for the caregiver to look after them. But, there were limited medical equipment and professionals for the patient to receive medical care at their homes. Hence, the patients with a terminal illness always need to go to the hospital for their critical illness management. However, to attend the medical appointments or in the case of an emergency, the caregiver's ability to bring the patient to the hospital is seen as a hard and difficult task to perform. The transport provided by the caregivers is not modified to be adapted to carry a bedridden patient. Using the transport without proper facilities seems to be not convenient to be used by patients with disabilities. As a result, most of the caregivers are unable to meet the needs of the patient to receive a proper medical treatment at the hospital. The study by Matthews et al. (2004) also found that the transportation resources specifically became a primary concern of the patients. Patients and their family members face the barrier to receiving a good quality care due to the lack of transportation resources. Furthermore, in a study of post-stroke patients, transportation selections were significantly important for safety, to attend hospital appointments, and increase independence (Marissa, Vento, Nakagawa and Linton, 2014).

Furthermore, the lack of resources or material needs of the patients also becomes a part of the barrier that is faced by caregivers. Caregivers claimed that it was difficult to find the material resources such as medical equipment to give the best care for the patients. Some degree of limitations to care that could be provided is a raised in the absence of equipment. This could relate to another core concept which is lack of financial means as well as insufficient supportive systems and the expensiveness of treatments (Tahrekhani, Sasani, \& Naji, 2015). In Iran for example, such an issue puts a heavy burden on the patients' families due to insufficient supportive care thus consequently can lead to a financial crisis (Tahrekhani, Sasani, \& Naji, 2015). However, by providing proper healthcare facilities it can lead to reduction in the number of hospitalization length; decrease the number of recurrence of the disease, and preservation of mental health and quality of life of both the patient and caregivers (Malakouti et al., 2004). Besides this, the government or other non-governmental organizations should look to this issue at hand and help to minimize the caregiver barriers to help them in providing the maximum quality of life in caregiving.

Meanwhile, the inconvenient home facilities also become a challenge for the caregivers in providing the care for an adult with terminal illnesses. Due to this issue, the caregivers need to provide their maximum physical demands in order to help the patients performing their tasks which lead to increase in caregivers' workload and burden to take care of the patient. This could be supported by a study that reported that the reduction of home environmental risks can improve functional performance of the patient with a disability and result in long-lasting benefits from both as a 
patient and their caregiver's quality of life (Serena et al. 2005). Therefore, this finding provides evidence for the health care professionals to assess the home environmental factor for ensuring home safety that motivates the patients to achieve their maximum independence that eventually will reduce the caregivers' burden.

\section{Limitation and Implications for Practice}

For limitations, in regards of transcribing and translation, the delicate description of the experience of caregiving barriers in the single Malay transcript may be translated such that the full intended meaning expressed by the caregiver could not be expressed accurately in English. Besides this, the limited number of participants also meant that the results could not be generalized to the targeted population.

This study contributes to the body of knowledge regarding the environmental barriers in adult terminal illness caregiving. It has been demonstrated throughout the real life experiences of the challenges and barrier issues in providing the care to the patients. By acknowledging these difficulties and barriers in caregivers to supportive care for an adult with terminal illnesses, researchers and health care professionals can begin to design and implement therapeutic interventions that are clinically relevant and more likely to be effective toward those most in need. In addition, involvement and recognition of the potential contributions from other helpful sources may help to reduce the burden on the caregivers as well as to promote better care for the adult with terminal illnesses.

\section{Conclusion and Recommendation}

In conclusion, environmental barriers distinguished by caregivers of adults with terminal illnesses are transportation, insufficient materials, and remote home facilities. Caregiving a difficult job as it is, and with limited environmental resources, caregiving could not only become a stressor to the persons involved but also to the patient, which in return could result in more negative consequences.

Future research should look into environmental intervention which includes adaptations and innovations that could be implemented for caregiving of the terminally ill patients. These interventions could be provided for the patient themselves or the caregivers. In addition, healthcare providers and policy makers can play a role by adopting a trans-disciplinary approach by identifying and integrating existing resources that could maximize assistance for the patients and caregivers.

\section{Acknowledgements}

The authors wish to thank the Research Management Centre of UiTM and the Ministry of Education for the permission to publish this paper and their invaluable support towards this study. The authors would also like to acknowledge the caregivers who have participated in this study. This study was funded by the Fundamental Research Grant Scheme [FRGS 600-RMI/FRGS 5/3 (29/2014)] under the Ministry of Education Malaysia.

\section{References}

Australian Bureau of Statistics (1999). Disability, ageing and carers: summary of findings.

Biggerstaff, D. L. \& Thompson, A. R. (2008). Interpretative Phenomenological Analysis (Ipa): A Qualitative Methodology Of Choice In Healthcare Research. Qualitative Research in Psychology, 5, 173 - 183

Bleich, S. N., Jarlenski, M. P., Bell, C. N., \& LaVeist, T. A. (2012). Health inequalities: Trends, progress, and policy. Annual Review of Public Health, 33, 7-40. 
Cubbin, C., LeClere, F. B., \& Smith, G. S. (2000). Socioeconomic status and the occurrence of fatal and nonfatal injury in the United States. American Journal of Public Health, 90(1), 70-77.

Drummond, M., Shemilt, I., Vale, L., \& on behalf of the Campbell and Cochrane Economic Methods Group (2013). Should The Cochrane Collaboration Be Producing Reviews of Efficiency? Cochrane Database of Systematic Reviews, 10, ED000071.

Gardiner, C., Brereton, L., Frey, R., Wilkinson-Meyers, L., \& Gott, M. (2014). Exploring the Financial Impact Of Caring For Family Members Receiving Palliative And End-Of-Life Care: A Systematic Review Of The Literature. Palliative Medicine, 28(5), 375-390.

Gonorazky, S. E. (2011). The Unresolved Issue of the "Terminal Disease" Concept. Health Management-Different Approaches and Solutions, 22, $415-432$.

Iwama, M. K., Thomson, N. A., \& Macdonald, R. M. (2009). The Kawa Model: the power of culturally responsive occupational therapy. Disability and Rehabilitation, 31, 1125-1135.

Janette, S. Dill, M. A., \& and Cagle, J. (2010). Caregiving in a Patient's Place of Residence: Turnover of Direct Care Workers in Home Care and Hospice Agencies. Journal of Aging and Health, 22(6), 713-733.

LaVeist, T., Pollack, K., Thorpe, R., Jr., Fesahazion, R., and Gaskin, D. (2011). Place, not race: Disparities dissipate in southwest Baltimore when blacks and whites live under similar conditions. Health Affairs, 30(10), 1880-1887.

Magnusson, A., Lützén, K., \& Severinsson, E. (2002). The influence of clinical supervision on ethical issues in home care of people with mental illness in Sweden. Journal of Nursing Management, 10, 37-45.

Matthews, B. A., Baker, F. \& Spillers, R. L. (2004). Oncology professionals and patient requests for cancer support services. Supportive Care in Cancer, 12(10), 731-738.

Malakoti, K., Nouri, R., Nasr, M. \& Asna, A., (2004). Effect of continuous care team activity in patients with chronic mental. ResearchQuarterly, 88, 5-13.

Marissa, M., Vento, M. A., Nakagawa, K.,\& Linton, K. F. (2014). A Qualitative Study of Transportation Challenges Among Intracerebral Hemorrhage Survivors and Their Caregivers. Hawai'I Journal of Medicine \& Public Health, 73(11).

Michalik, J., \& Valenta, M. (2012). Family caring for a family member with the severe disability as a specific group of clients of helping professions. Procedia - Social and Behavioral Sciences, 69, 467-476.

Petkova, M., Nikolov, V., Galabova, M., \& Petrova, B. (2010). Psychological assessment of cancer patients with chronic pain. Procedia - Social and Behavioral Sciences, 5, 421-425.

Pinquart, M., \& Sörensen, S. (2005). Ethnic differences in stressors, resources, and psychological outcomes of family caregiving: A metaanalysis. The Gerontologist, 45(1), 90-106.

Ryn, M. V., Sanders, S., Kahn, K., Houtven, C. V....Rowland, J. et al. (2011). Objective burden, resources, and other stressors among informal cancer caregivers: a hidden quality issue? Psycho-Oncology, 20, 44-52.

Serena, N., Chu, M., Wu, A., \& Cheung, P. (2005). Effectiveness of Home-based Occupational Therapy for Early Discharged Patients with Stroke. Hong Kong Journal of Occupational Therapy, 15, 27-36.

Sherman, D. W. (1998). Reciprocal suffering: the need to improve family caregivers' quality of life through palliative care. Journal of PalliativeMedicine, 1(4), 357-366.

Smith, J. A. (2004). Reflecting On The Development Of Interpretative Phenomenological Analysis And Its Contribution To Qualitative Research In Psychology. Qualitative Research in Psychology, 1, 39 - 54.

Smith, J. A., Flowers, P., \& Larkin, M. (2009).Interpretative phenomenological analysis: Theory, method and research. London: Sage, (Chapter5 $\& 6)$.

Socialstyrelsen (2008). Health: Progress Report 2007. National Board of Health and Welfare, Stockholm. ISBN: 978-91-85999-10-1.

Tehrekhani, M., Sasani, L., \& Naji, S. (2015). Shared Experiences of the Families of Female Patients Suffering from the Manic Phase of Bi-Polar Disorder. Procedia- Social and Behavioral Sciences, vol. 185, pp. 333-338.

Tse Man Wah, D. (2007). Care for the Family in Palliative Care. Palliative Medicine Doctors' Meeting. Hong Kong Society of PalliativeMedicine Newsletter, 1\&2, 26-30. 
Stone, R. I. (2001). Research on frontline workers in long-term care. Generations, 25, 49-57.

WHO Centre for Health Development Ageing and Health Technical Report (2004). A Glossary of Terms For Community Health Care And Services For Older Persons World Health Organization .Vol. 5. Japan.

Wilhelmsson, A.B (2011). Relatives' experiences of care and caregivers in a psychiatric caring context. Procedia-Social and Behavioral Sciences, vol. 30, pp. 2296-2304.

Woolf, S. H. \& Aron, L. (2013). U.S. Health in International Perspective: Shorter Lives, Poorer Health.The International Academic Press:Washington D.C. 